\title{
Dearomative Allylation of Aromatic Cyanohydrins by Palladium Ca- talysis: Catalyst-Enhanced Site-Selectivity
}

\author{
Aika Yanagimoto, Masaaki Komatsuda, Kei Muto*, Junichiro Yamaguchi* \\ Department of Applied Chemistry, Waseda University, 3-4-1, Ohkubo, Shinjuku, Tokyo, 169-8555, Japan \\ Supporting Information Placeholder
}

ABSTRACT: A dearomative allylation of aromatic cyanohydrins with allyl borates and allyl stannanes under palladium catalysis was developed. At the initial stage of this study, the dearomative reaction (C4substitution of the aromatics) was competing with benzyl substitution. To circumvent this issue, the use of palladium and meta-disubstituted triarylphosphine as the catalyst in a 1:1 ratio was found to enhance the site-selectivity, furnishing the desired dearomatized products. As the products possess an unsaturated nitrile moiety, further derivatizations of products such as conjugate additions and reductions were achieved.

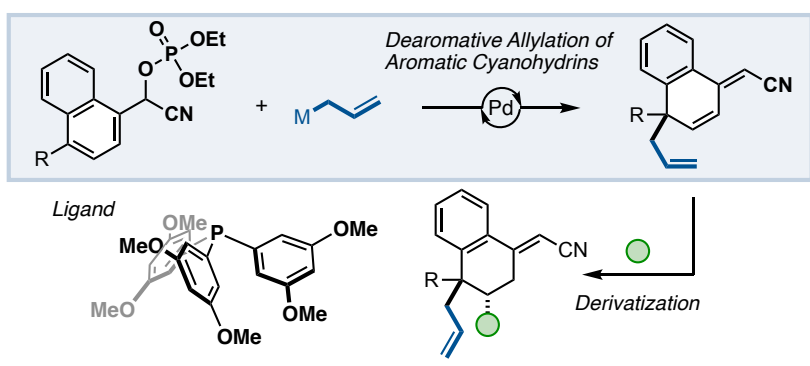

The chemical transformation of arenes is a fundamental topic in organic synthesis. Many transformations of arenes have been developed, of which electrophilic aromatic substitutions and crosscouplings are recognized as key functionalizations of $\sigma$-bonds of aromatic cores. ${ }^{[1]}$ On the other hand, the transformation of ring itself, i.e., the transformation of the $\pi$-bonds of arenes such as dearomative reactions is less studied. Nevertheless, this type of reaction can provide high molecular complexity from simple and abundant arenes. With recent developments in metal-catalysis, several dearomatization methods have emerged. ${ }^{[2]}$ For example, the Glorius group recently achieved efficient hydrogenations of arenes to give birth alicyclic compounds with a high stereo-control. ${ }^{[2-f]}$ For dearomative functionalizations, however there are more limitations than with hydrogenations. For example, the efficiency of the reaction significantly depends on the electronic nature of the arenes. Although electron-rich and electron-poor arenes can mostly be utilized as a limiting agent, ${ }^{[3]}$ electron-neutral arenes are regarded as inactive arenes, usually requiring excess amounts in a reaction. ${ }^{[4,5]}$ Generally, only nitroarenes ${ }^{[6]}$, aryl malonates ${ }^{[7]}$, and aryl iodanes ${ }^{[8]}$ can be utilized for dearomative functionalizations as the limiting reagent.

We recently reported the dearomative allylation of inactive aromatic systems initiated by a catalytic bond cleavage (Figure 1A). ${ }^{[9]}$ So far, we developed the dearomative allylation of benzyl phosphates $^{[9 a]}$ as well as aryl bromides ${ }^{[9 b]}$ under the influence of a palladium catalyst. Yamamoto and Bao also developed related reactions involving benzyl chlorides. ${ }^{[10]}$ These methods enabled the dearomative functionalization of inactive arenes as a limiting reagent. However, the obtained products were unstable and difficult to derivatize to functionalized alicyclic systems, that restricting further synthetic application. We postulated that this instability was caused by the highly reactive exocyclic olefin of the products. To achieve

the dearomative synthesis of multi-functionalized alicyclic molecules, we selected aromatic cyanohydrin phosphates as the substrate, ${ }^{[11]}$ which possess a cyano group at the benzyl position (Figure $1 \mathrm{~B})$. These were readily prepared from the corresponding aldehydes in one step. ${ }^{[12]}$ More importantly, since the dearomatized products have an $\alpha, \beta$-unsaturated cyano moiety, they are expected to be functionalized through a conjugate addition. With this application in mind, we herein report the development of dearomative allylation of aromatic cyanohydrins by a palladium catalyst.

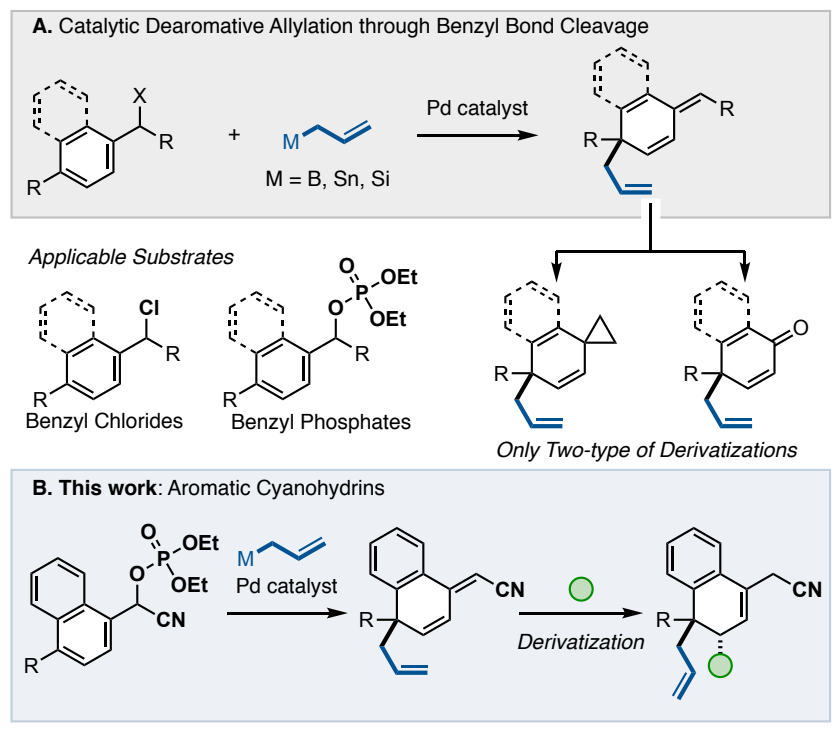

Figure 1. (A) Catalytic dearomative allylation. (B) Dearomative allylation of aromatic cyanohydrins 
We initiated this study by investigating the reaction conditions using naphthalene cyanohydrin $\mathbf{1 A}$ with allyl trifluoroborate $\mathbf{2 a}$ (Table 1). As a first trial, our previous reaction conditions for dearomative allylation of benzyl phosphates were examined (Table 1, entry 1). ${ }^{[9 a]}$ However, the reactivity of cyanohydrins and simple benzyl phosphates are rather different for this catalytic system, generating only the undesired benzyl-substituted product $4 \mathrm{~A}$ in $83 \%$ yield. We hypothesized that this site-selectivity occurred due to the highly electrophilic nature of the $\alpha$-cyano moiety leading to undesired benzyl substitution. Thus, the reaction temperature was decreased from $60{ }^{\circ} \mathrm{C}$ to room temperature. To our delight, the dearomative reaction proceeded to give the desired product (dearomative allylation product) $3 \mathrm{~A}$ in $40 \%$ yield, along with the undesired $4 \mathrm{~A}$ in a ratio of $1: 1$ (Table 1 , entry 2 ). Lowering the reaction temperature to $4{ }^{\circ} \mathrm{C}$ resulted in no reaction (Table 1 , entry 3 ). Interestingly, when the ratio of metal/ligand was changed, decreasing the amount of ligand improved this site-selectivity (Table 1, entry 2 vs. entries 4 and 5). Next, the effect of the ligand was investigated. Simple $\mathrm{PPh}_{3}$ decreased the yield of $3 \mathrm{~A}$ and $\mathbf{4 A}$ while retaining the site-selectivity (Table 1 , entry 6 ). When using $o$-, $m$-, and $p$ tolyl phosphines, it was found that $m$-tolyl phosphine was effective (Table 1, entries 7-9). Encouraged by the effect of metasubstituents, we synthesized and evaluated several $m$-disubstituted triarylphosphines (Table 1, entries 10-13). As a result, electronrich $m$-disubstituted triarylphosphines were

\section{Table 1. Screening of Reaction Conditions ${ }^{a}$}

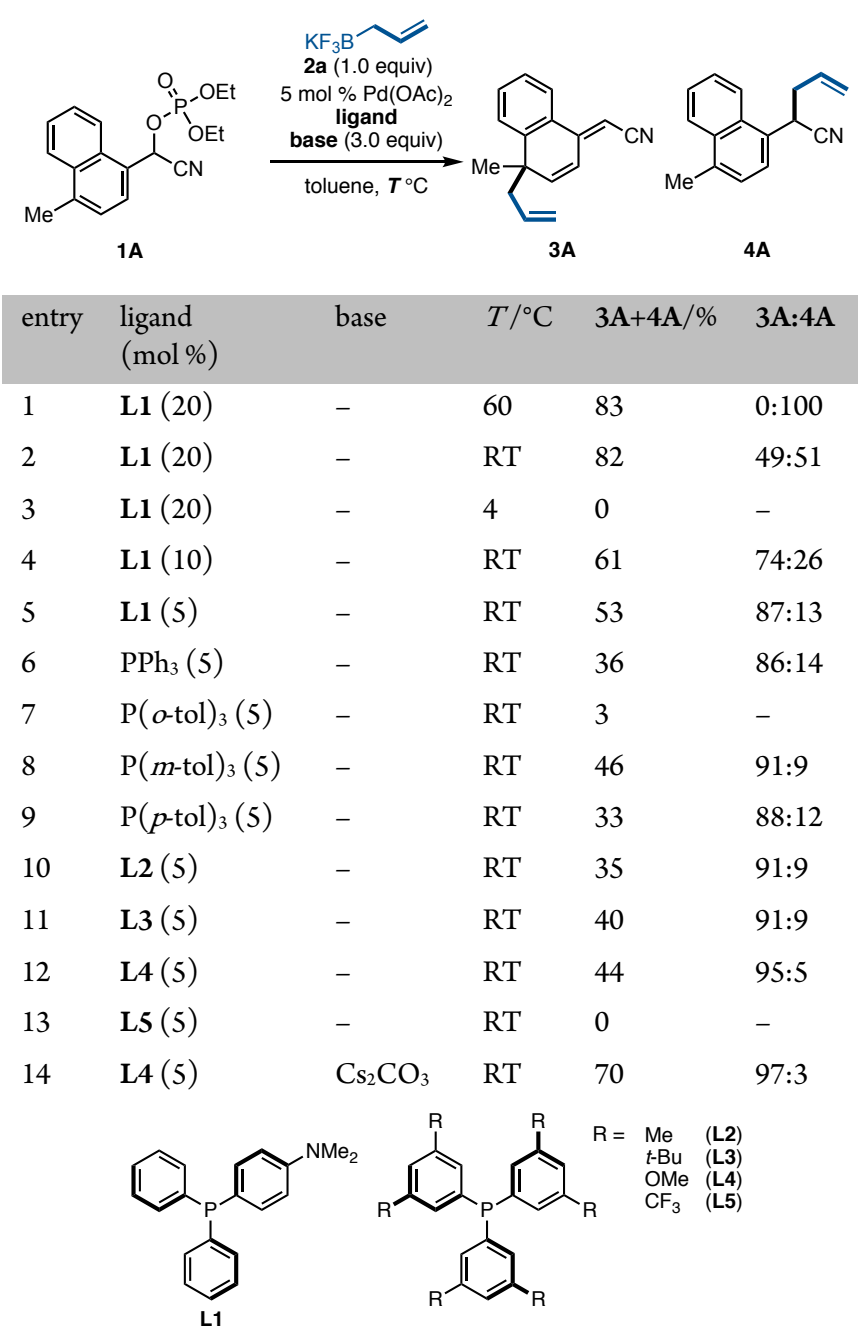

${ }^{a}$ Conditions: 1A (0.20 mmol), $2(0.20 \mathrm{mmol}), \mathrm{Pd}(\mathrm{OAc})_{2}(5 \mathrm{~mol} \%)$, ligand, base (3.0 equiv), toluene $(1.0 \mathrm{~mL}), 12 \mathrm{~h} .{ }^{b} \mathrm{NMR}$ yield.

found to be favorable for both reaction yield and site-selectivity, out of which $m$-dimethoxyphenyl phosphine $\mathbf{L} 4$ gave the best result (Table 1, entry 12). Delightfully, the addition of $\mathrm{Cs}_{2} \mathrm{CO}_{3}$ as a base improved the reaction efficiency, furnishing the product $\mathbf{3 A}$ in $70 \%$ yield with high site-selectivity (Table 1, entry 14).

With the optimized conditions in hand, we evaluated the substrate scope of the present reactions (Scheme 1). The reaction was applicable to C4-substituted naphthalenes. Several C4-alkylated naphthalene cyanohydrins underwent the reaction, giving the corresponding products 3 in moderate to good yields with high siteselectivity (3A-3C). A sterically demanding isopropyl group was also compatible in this reaction (3D). A strained alkyl group such as cyclopropyl was tolerated to give $3 \mathrm{E}$ in moderate yield. Reactive functional groups such as acetal (3G), ester (3I), and silyloxy group (3J) were intact under the reaction conditions. Furthermore, allyl stannane was found to be applicable as the allylating agent in the absence of base, furnishing $\mathbf{3 A}$ in good yield with high siteselectivity. It is noteworthy that these dearomatized products were reasonably stable, not decomposing during silica-gel column chromatography.

Scheme 1. Substrate Scope ${ }^{a}$

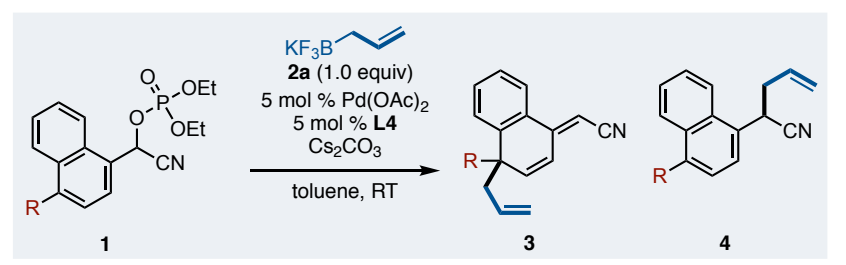

Isolated yield (ratio of 3:4)
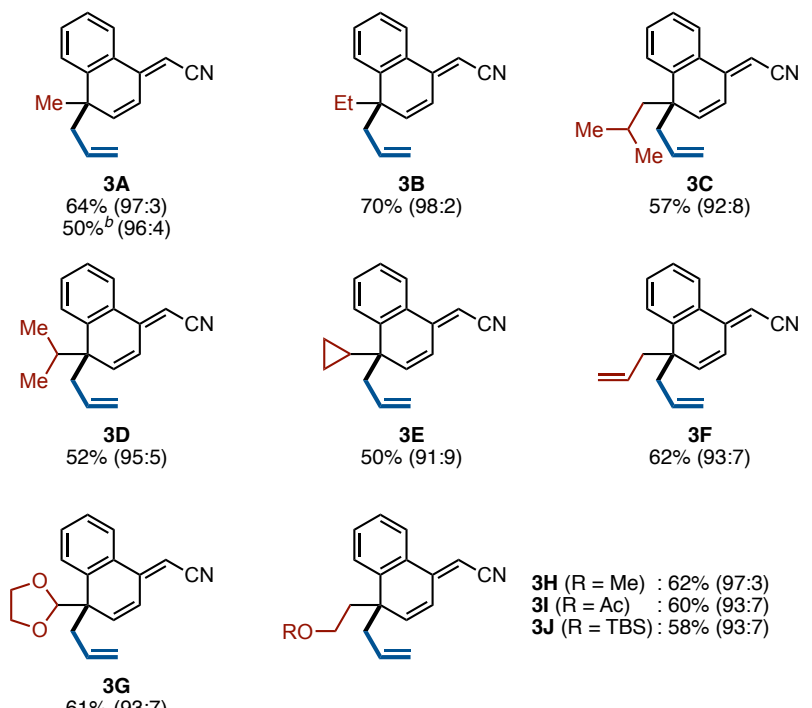

$61 \%(93: 7)$

- Using allyl stannane

Isolated yield (ratio of 3:4)

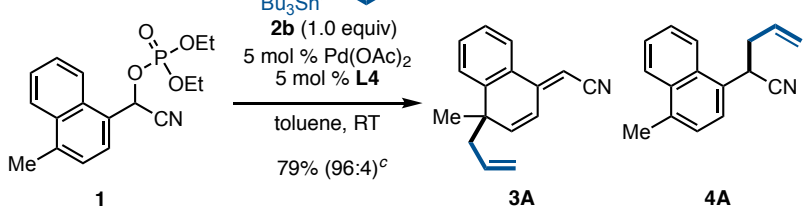

${ }^{a}$ Conditions. 1 (0.20 mmol), $2 \mathrm{a}(0.20 \mathrm{mmol}), \mathrm{Pd}(\mathrm{OAc})_{2}(5 \mathrm{~mol} \%)$, L4 (5 mol \%), $\mathrm{Cs}_{2} \mathrm{CO}_{3}$ (3.0 equiv), toluene (1.0 mL), RT, 12 h. $^{b} 1.0$ mmol scale. ${ }^{b}$ Determined by ${ }^{1} \mathrm{H}$ NMR. 
A possible reaction mechanism is outlined in Scheme 2. ${ }^{[13]}$ First oxidative addition of $\mathrm{C}-\mathrm{O}$ bonds to palladium(0) species gives benzyl-palladium $\mathbf{B}$, which is in equilibrium between $\sigma$ - and $\pi$ benzyl species. To this species, allyl borates undergo transmetalation, generating allyl-palladium-benzyl intermediate C. Finally, reductive elimination forms the $\mathrm{C}-\mathrm{C}$ bond at the remote-site, releasing the dearomatized products with regeneration of the active palladium $(0)$ species. $^{[14]}$

Scheme 2. Proposed Mechanism.

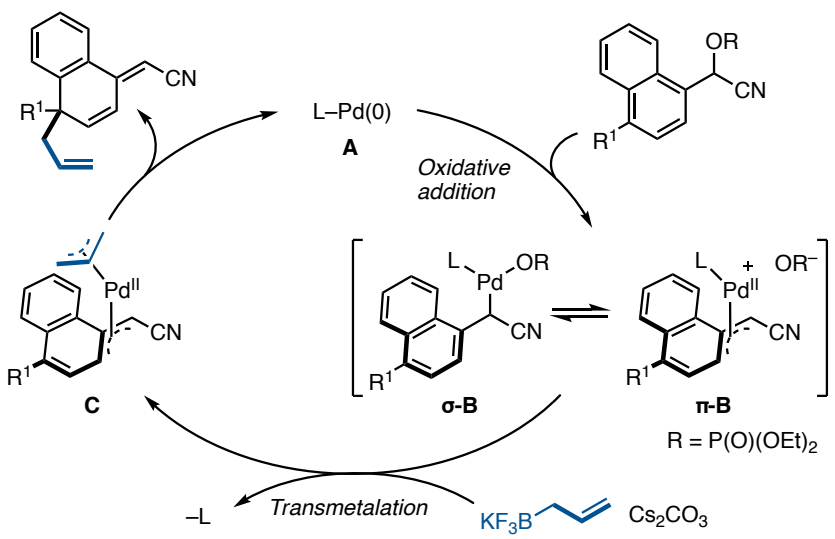

At this stage, we speculate that the observed catalyst-enhanced site-selectivity may be triggered by the generation of coordinatively unsaturated palladium species $\mathbf{B}$ (Scheme 3 ). The reaction conditions using a 1:1 ratio of palladium and ligand would generate a coordinatively unsaturated palladium intermediate. Thus, the allyl boron species can undergo transmetalation to give the allyl-Pdbenzyl intermediate, followed by reductive elimination at the $\mathrm{C} 4$ position to furnish the dearomatized product. ${ }^{[14]}$ In contrast, when palladium and ligand were used in a ratio of $1: 2$ or more, coordinatively saturated species $\mathbf{D}$ would be generated as the major catalytic intermediate. Probably due to the highly electrophilic nature of the cyano-bearing benzyl carbon, the allyl borons likely prefers external attack onto $\mathbf{D}$, giving the benzyl-substituted compound as the major product.

meta-Disubstituted triarylphosphines likely enforce the generation of coordinatively unsaturated palladium $\mathbf{B}$ by steric repulsion. According to Tsuji's work, meta-disubstituted triarylphosphines have a bowl-shaped structure, accelerating the dissociation of other ligands but providing reaction space around the metal center. ${ }^{[15]}$ In line with these reports, the use of meta-disubstituted triarylphosphines would support the generation of a coordinatively unsaturated palladium species in this catalytic system.

Scheme 3. Possible Role of Catalyst for Site-Selectivity.
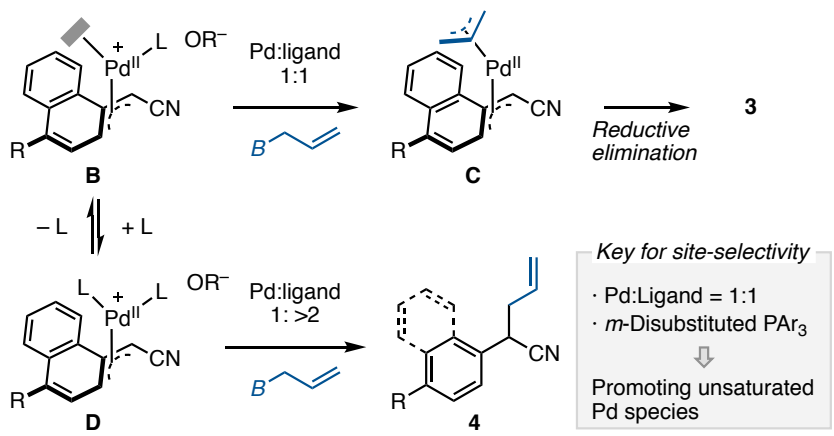

Although $o$-substituted triarylphosphines are also expected to give coordinatively unsaturated palladiums, they cannot provide enough reaction space around the metal center, blocking the desired transmetalation of allyl borons. ${ }^{[16]}$

Finally, we performed several transformations of dearomatized product 3A (Scheme 4). The $\alpha, \beta$-unsaturated cyano moiety is expected to be functionalized through several nucleophilic additions. Although we expected that 1,4-addition would occur when using carbon nucleophiles, the reaction using lithioacetonitrile afforded 1,6-adduct 5 instead. A similar regioselectivity was observed when nitromethane was reacted with $3 \mathrm{~A}$ in the presence of $\mathrm{DBU}$, furnishing 6. This regioselectivity is likely due to the steric repulsion of the $\delta, \gamma$-unsaturated olefin (disubstituted) vs the $\alpha, \beta$-unsaturated olefin (trisubstituted) to circumvent the expected 1,4-addition. Furthermore, we succeeded in the reductive derivatization of $3 \mathbf{A}$ through global hydrogenation, furnishing substituted tetralin 7 . Treatment of 3 A with DIBAL was also successful to deliver enal 8.

Scheme 4. Derivatization of $3 A$.
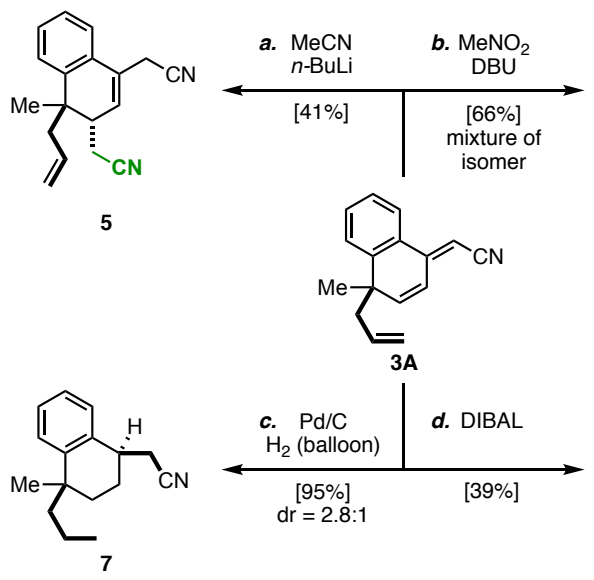

CN
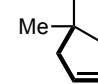

$\underline{3 A}$

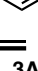

In summary, we developed a dearomative allylation of aromatic cyanohydrins by a palladium catalyst. The combination of palladium and $m$-disubstituted triarylphosphines enhanced site-selectivity, furnishing dearomatized molecules. Importantly, the dearomatized products were able to be derivatized to a variety of substituted alicyclic systems. We believe that the present work would provide a useful synthetic entry to alicyclic molecules and lead to an in-depth understanding of the mechanism of related reactions. Further studies to expand the substrate generality and elucidate the mechanism are ongoing in our laboratory.

\section{ASSOCIATED CONTENT}

\section{Supporting Information}

Experimental procedures and spectroscopic data for compounds including ${ }^{1} \mathrm{H},{ }^{13} \mathrm{C},{ }^{31} \mathrm{P}$ NMR spectra (PDF)

\section{AUTHOR INFORMATION}

\section{Corresponding Author}

*keimuto@aoni.waseda.jp

*junyamaguchi@waseda.jp

Notes

No competing financial interests have been declared. 


\section{ORCID}

Kei Muto: 0000-0001-8301-4384

Junichiro Yamaguchi: 0000-0002-3896-5882

\section{ACKNOWLEDGMENT}

This work was supported by JSPS KAKENHI Grant Number JP19H02726 (to J.Y.), JP18H04661 (Hybrid Catalysis), JP19K15573, and The SATOMI Scholarship Foundation (to K.M.). The Materials Characterization Central Laboratory in Waseda University is acknowledged for HRMS measurement.

\section{REFERENCES}

(1) Metal-Catalyzed Cross-Coupling Reactions, and More, 1, 2 and 3; de Meijere, A., Bräse, S., Oestreich, M., Eds.; Wiley-VCH: Weinheim, Germany, 2013.

(2) For a review, see: (a) Wang, D.-S.; Chen, Q.-A.; Lu, S.-M.; Zhou, Y.G. Asymmetric Hydrogenation of Heteroarenes and Arenes. Chem. Rev. 2011, 112, 2557-2590. (b) Wiesenfeldt, M. P.; Nairoukh, Z.; Dalton, T.; Glorius, F. Selective Arene Hydrogenation for Direct Access to Saturated Carbo- and Heterocycles. Angew. Chem., Int. Ed. 2019, 58, 10460-10476. Selected recent examples on catalytic hydrogenation of arenes, see: (c) Wiesenfeldt, M. P.; Nairoukh, Z.; Li, W.; Glorius, F. Hydrogenation of Fluoroarenes: Direct Access to All-cis-(Multi)fluorinated Cycloalkanes. Science 2017, 357, 908-912. (d) Wiesenfeldt, M. P.; Knecht, T.; Schlepphorst, C.; Glorius, F. Silylarene Hydrogenation: A Strategic Approach that Enables Direct Access to Versatile Silylated Saturated Carbo- and Heterocycles. Angew. Chem., Int. Ed. 2018, 57, 8297-8300. (e) Nairoukh, Z.; Wollenburg, M.; Schlepphorst, C.; Bergander, K.; Glorius, F. The Formation of All-cis-(Multi)fluorinated Piperidines by a DearomatizationHydrogenation Process. Nat. Chem. 2019, 11, 264-270. (f) Wollenburg, M.; Moock, D.; Glorius, F. Hydrogenation of Borylated Arenes. Angew. Chem., Int. Ed. 2019, 58, 6549-6553.

(3) (a) Roche, S. P.; Porco, J. A. Dearomatization Strategies in the Synthesis of Complex Natural Products. Angew. Chem., Int. Ed. 2011, 50, 4068-4093. (b) Zhuo, C.-X.; Zhang, W.; You, S.-L. Catalytic Asymmetric Dearomatization Reactions. Angew. Chem., Int. Ed. 2012, 51, 12662 12686. (c) Wu, W.-T.; Zhang, L.; You, S.-L. Catalytic Asymmetric Dearomatization (CADA) Reactions of Phenol and Aniline Derivatives. Chem. Soc. Rev. 2016, 45, 1570-1580. (d) Zheng, C. You, S.-L. Catalytic Asymmetric Dearomatization by Transition-Metal Catalysis: A Method for Transformations of Aromatic Compounds. Chem 2016, 1, 830-857. (e) Liang, X.-W.; Zheng, C.; You, S.-L. Dearomatization through Halofunctionalization Reactions. Chem. Eur. J. 2016, 22, 11918-11933.

(4) For reviews, see:(a) Pape, A. R.; Kaliappan, K. P.; Kündig, E. P. Transition-Metal-Mediated Dearomatization Reactions. Chem. Rev. 2000, 100, 2917-2940. (b) Hudlický, T. Recent Chemoenzymatic Total Syntheses of Natural and Unnatural Products: Codeine, Balanol, Pancratistatin, and Oseltamivir. Pure Appl. Chem. 2010, 82, 1785-1796. (c) Duchek, J.; Adams, D. R.; Hudlicky, T. Chemoenzymatic Synthesis of Inositols, Conduritols, and Cyclitol Analogues. Chem. Rev. 2011, 111, 4223-4258. (d) Wertjes, W. C.; Southgate, E. H.; Sarlah, D. Recent Advances in Chemical Dearomatization of Nonactivated Arenes. Chem. Soc. Rev. 2018, 47, 7996-8017.

(5) For selected examples, see: (a) Southgate, E. H.; Pospech, J.; Fu, J.; Holycross, D. R.; Sarlah, D. Dearomative Dihydroxylation with Arenophiles. Nat. Chem. 2016, 8, 922-928. (b) Okumura, M.; Nakamata Huynh, S. M.; Pospech, J.; Sarlah, D. Arenophile-Mediated Dearomative Reduction. Angew. Chem., Int. Ed. 2016, 55, 15910-15914. (f) Okumura, M.; Shved, A. S.; Sarlah, D. Palladium-Catalyzed Dearomative syn-1,4Carboamination. J. Am. Chem. Soc. 2017, 139, 17787-17790. (g) Hernandez, L. W.; Klöckner, U.; Pospech, J.; Hauss, L.; Sarlah, D. NickelCatalyzed Dearomative trans-1,2-Carboamination. J. Am. Chem. Soc. 2018, 140, 4503-4507. (h) Hamrock, S. J.; Sheridan, R. S. Para Photoaddition of $\mathrm{N}$-Methyltriazolinedione to Benzene. Synthesis of Energy-Rich Azo Compounds Comprising Benzene + Nitrogen. J. Am. Chem. Soc. 1989, 111, 9247-9249. (i) Fujita, M.; Matsushima, H.; Sugimura, T.; Tai, A.; Okuya- ma, T. Asymmetric Addition of an Electrophile to Naphthalenes Promoted and Stereodirected by Alcohol. J. Am. Chem. Soc. 2001, 123, 2946-2957.

(6) Trost, B. M.; Ehmke, V.; O’Keefe, B. M.; Bringley, D. A. PalladiumCatalyzed Dearomative Trimethylenemethane Cycloaddition Reactions. J. Am. Chem. Soc. 2014, 136, 8213-8216.

(7) Yang, Z.-P.; Jiang, R.; Wu, Q.-F.; Huang, L.; Zheng, C.; You, S.-L. Iridium-Catalyzed Intramolecular Asymmetric Allylic Dearomatization of Benzene Derivatives. Angew. Chem., Int. Ed. 2018, 57, 16190-16193.

(8) Zhao, W.; Huang, X.; Zhan, Y.; Zhang, Q.; Li, D.; Zhang, Y.; Kong, L.; Peng, B. Dearomative Dual Functionalization of Aryl Iodanes. Angew. Chem., Int. Ed. 2019, 58, 17210-17214.

(9) (a) Komatsuda, M.; Muto, K.; Yamaguchi, J. Pd-Catalyzed Dearomative Allylation of Benzyl Phosphates. Org. Lett. 2018, 20, 43544357. (b) Komatsuda, M.; Kato, H.; Muto, K.; Yamaguchi, J. Pd-Catalyzed Dearomative Three-Component Reaction of Bromoarenes with Diazo Compounds and Allylborates. ACS Catal. 2019, 9, 8991-8995.

(10) (a) Bao, M.; Nakamura, H.; Yamamoto, Y. Facile Allylative Dearomatization Catalyzed by Palladium. J. Am. Chem. Soc. 2001, 123, 759-760. (b) Peng, B.; Feng, X.; Zhang, X.; Ji, L.; Bao, M. Regioselective Control Using a Catalyst Switch in the Reaction of Diarylmethyl Chlorides with Allyltributylstannane. Tetrahedron 2010, 66, 6013-6018. (c) Zhang, S.; Yu, X.; Feng, X.; Yamamoto, Y.; Bao, M. Palladium-Catalyzed Regioselective Allylation of Five-Membered Heteroarenes with Allyltributylstannane. Chem. Commun. 2015, 51, 3842-3845. (d) Zhang, S.; Cai, J.; Yamamoto, Y.; Bao, M. Palladium-Catalyzed $\mathrm{sp}^{2}-\mathrm{sp}^{3}$ Coupling of Chloromethylarenes with Allyltrimethoxysilane: Synthesis of Allyl Arenes. J. Org. Chem. 2017, 82, 5974-5980. (e) Zhang, S.; Ullah, A.; Yamamoto, Y.; Bao, M. Palladium-Catalyzed Regioselective Allylation of Chloromethyl(hetero)arenes with Allyl Pinacolborate. Adv. Synth. Catal. 2017, 359, 2723-2728.

(11) For the catalytic reaction of aromatic cyanohydrins, only coupling reactions are known. See: He, A.; Falck, J. R. Stereospecific Suzuki CrossCoupling of Alkyl $\alpha$-Cyanohydrin Triflates. J. Am. Chem. Soc. 2010, 132, 2524-2525.

(12) (a) Kurihara, T.; Santo, K.; Harusawa, S.; Yoneda, R. Application of Cyanophosphates in Organic Synthesis. Reactivity of $\alpha$-Cyano- $\alpha-$ Diethylphosphonooxy Anions. Chem. Pharm. Bull. 1987, 35, 4777-4788. (b) Mizuno, M.; Shioiri, T. Reaction of Carboxylic Acids with Diethyl Phosphorocyanidate; A Novel Synthesis of Homologated aHydroxycarboxylic Acids from Carboxylic Acids. Tetrahedron Lett. 1998, 39, 9209-9210.

(13) Ariafard, A.; Lin, Z. DFT Studies on the Mechanism of Allylative Dearomatization Catalyzed by Palladium. J. Am. Chem. Soc. 2006, 128, 13010-13016.

(14) For related 3,3'-reductive eliminations of bis- $\pi$-allyl palladium species, see: (a) Méndez, M.; Cuerva, J. M.; Gómez-Bengoa, E.; Cárdenas, D. J.; Echavarren, A. M. Intramolecular Coupling of Allyl Carboxylates with Allyl Stannanes and Allyl Silanes: A New Type of Reductive Elimination Reaction?. Chem. Eur. J. 2002, 8, 3620-3628. (b) García-Iglesias, M.; Buñuel, E.; Cardenas, D. J. Cationic ( $\eta^{1}$-Allyl)-palladium Complexes as Feasible Intermediates in Catalyzed Reactions. Organometallics 2006, 25 , 3611-3618. (c) Sieber, J. D.; Liu, S.; Morken, J. P. Catalytic Conjugate Addition of Allyl Groups to Styryl-Activated Enones. J. Am. Chem. Soc. 2007, 129, 2214-2215. (d) Keith, J. A.; Behenna, D. C.; Sherden, N.; Mohr, J. T.; Ma, S.; Marinescu, S. C.; Nielsen, R. J.; Oxgaard, J.; Stoltz, B. M.; Goddard, W. A. The Reaction Mechanism of the Enantioselective Tsuji Allylation: Inner-Sphere and Outer-Sphere Pathways, Internal Rearrangements, and Asymmetric C-C Bond Formation. J. Am. Chem. Soc. 2012, 134, 19050-19060.

(15) (a) Niyomura, O.; Tokunaga, M.; Obora, Y.; Iwasawa, T.; Tsuji, Y. Rate Enhancement with a Bowl-Shaped Phosphane in the RhodiumCatalyzed Hydrosilylation of Ketones. Angew. Chem., Int. Ed. 2003, 42, 1287-1289. (b) Ohta, H.; Tokunaga, M.; Obora, Y.; Iwai, T.; Iwasawa, T.; Fujihara, T.; Tsuji, Y. A Bowl-Shaped Phosphine as a Ligand in PalladiumCatalyzed Suzuki-Miyaura Coupling of Aryl Chlorides: Effect of the Depth of the Bowl. Org. Lett. 2007, 9, 89-92. (c) Fujihara, T.; Semba, K.; Terao, J.; Tsuji, Y. Copper-Catalyzed Hydrosilylation with a Bowl-Shaped 
